\title{
miRNA Control of Tissue Repair and Regeneration
}

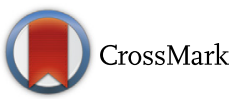

\author{
Chandan K. Sen and Subhadip Ghatak
}

From the Center for Regenerative Medicine and Cell-Based Therapies and the Department of Surgery, The Ohio State University Wexner Medical Center, Columbus, Ohio

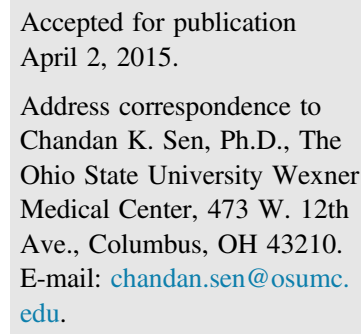

Injury-responsive coding genes are recognized as a main driver of wound healing and tissue regeneration. ${ }^{1}$ After injury, tissue healing is initiated either by regeneration or repair or by a combination of both. Although robust tissue regeneration is observed in certain lower vertebrates, including urodele amphibians and teleost fish, mammalian tissue regeneration is limited, particularly in adults. ${ }^{2}$ A cornerstone in the process of regeneration is the expression of injury-inducible coding genes at the site of tissue injury. However, simultaneous expression of an array of injury responsive coding genes, after injury, complicates signaling networks. Post-transcriptional gene silencing (PTGS) may be viewed as a filter that is aimed at selectively advancing limited sets of injury-responsive coding genes toward protein expression to streamline the repair and regeneration process.

Earlier, approximately $97 \%$ of human DNA was considered as junk because it did not encode for protein. ${ }^{3}$ However, the current literature recognizes a critical role of noncoding DNA in biology. What used to be known as junk DNA is now known to produce approximately 22nucleotide long evolutionarily conserved and functionally critical single-stranded miRNA molecules that specifically silence mRNA function predominantly by accessing the $3^{\prime}$ untranslated regions of mRNA. ${ }^{4}$ Chromatin silencing, repression of translation, and mRNA degradation are mechanisms by which miRNAs implement PTGS in a sequence-specific inhibition manner. ${ }^{5}$ Thus, miRNA biology determines the biological functionality of coding genes.

According to the current edition of miRbase, a central online repository for miRNAs, there are 1881 hairpin precursors and 2588 mature miRNAs enlisted for humans. This list is rapidly expanding. Because the function of miRNA determines the functional fate of mRNA, understanding the implication of miRNA in the context of tissue repair and regeneration becomes critically important. Here, we discuss the developments recorded in the current literature that underscore the rapidly unfolding importance

Supported by NIH/National Institute of General Medical Sciences grants GM069589, GM077185, GM108014, and NR013898 (C.K.S.).

Disclosures: None declared.

This article is part of a review series on regenerative medicine. 
of miRNA and related processes in tissue regeneration and repair.

\section{Development Is the Key to Regeneration}

In mammals, the early in utero state has provided some of the most impressive evidence of tissue regeneration. ${ }^{6}$ Such remarkable regenerative potential is markedly blunted or lost in the postnatal period and more so during adulthood and old age. Comparison of the global expression pattern of mature miRNA of mouse fetal skin from different developmental stages has provided critical insight into miRNA-based regulation of adult tissue development. ${ }^{7}$ Healing of the skin at embryonic day (E)16 is regenerative and scarless and was associated with global miRNA repression compared with the skin of E19. The healing at this stage featured adult phenotype, including scar formation. ${ }^{7}$ Of note in this context is the observation that miRNA biogenesis is substantially blunted at E16, indicative of dampened PTGS in the fetal skin. Global suppression of miRNA function has been consistently noted in mouse oocytes and early embryo. ${ }^{8}$ The global suppression of miRNA during mouse oocyte-to-embryo transition is likely facilitated by the expression of highly conserved RNA binding proteins Lin28a and Lin28b that are abundant during embryogenesis. ${ }^{9}$ Down-regulation of let-7 miRNA is initiated by the pluripotent factor Lin 28 by onset of let-7 precursor (pre-let-7) uridylation using a noncanonical poly(A) polymerase, TUTase4 (TUT4). ${ }^{10}$ These reports lead to the hypothesis that fetal tissue development is enabled by transiently silencing miRNA-dependent PTGS. Such silencing of the silencer unleashes numerous additional coding genes important for tissue development. ${ }^{11}$

After spinal cord injury in Wistar rats, miRNA expression is markedly subdued from day 3 after injury with gradual rebound of down-regulated miRNA at 7 days after injury. ${ }^{12}$ Suppression of miRNA expression after spinal cord injury was verified in an independent study in which downregulated miRNAs were reported up to 14 days after injury. ${ }^{13}$ The pattern of miRNA suppression after injury holds across organ systems. Partial hepatectomy is followed by down-regulation of $70 \%$ of the miRNA within 24 hours of injury. Of particular interest in this study was the observation that miRNA down-regulation was preceded by a transient upregulation of miRNA 3 hours after injury, a response aimed at directing liver regeneration. The subsequent genome-wide suppression of miRNAs supported tissue regeneration by restoration of liver cell mass. In patients undergoing auxiliary liver transplantation, down-regulation of miRNA facilitated cell proliferation that supported tissue regeneration. ${ }^{14}$ In similar cohorts suffering from failed regeneration, expression of specific miRNA regulating cell cycle inhibition and DNA methylation were identified. ${ }^{14}$ Taken together, these observations support the hypothesis there is support for the notion that injury-induced suppression of miRNAs may serve as an intrinsic physiological strategy to transiently desilence coding genes necessary for the tissue repair and regeneration processes.

In adult tissue, resident stem cells (SCs) are usually postmitotic and quiescent and are substantially different from embryonic SCs (ESCs), which are actively proliferating and differentiating. ${ }^{15}$ However, external stimuli in the form of injury may suppress tissue-specific miRNAs, which in turn may lead to alterations in adult resident SCs such that they start to differentiate, akin to their embryonic counterpart, with the objective to enact tissue repair. This is one example of how regeneration is largely inspired by mechanistic underpinning of embryo development. Some of the widespread principles and processes that drive tissue regeneration include cellular differentiation, dedifferentiation, transdifferentiation, and reprogramming. ${ }^{16}$

\section{Dedifferentiation, Transdifferentiation, and Cellular Reprogramming}

Unlike lower vertebrates, mammalian tissue regeneration or repair processes rely on pre-existing stem and other cells with plasticity to replace the injured tissue. ${ }^{17}$ The sources of such cell populations are limited. In response to a strong microenvironmental cue triggered by the injury, behavior of some of the cells in close proximity of the injury site changes to accommodate the emergence of new cell types. Plasticity of surviving cells at or close to the injury site provides additional pools of cell populations that may contribute to the repair or regeneration process. Using a fluorescent-labeled tracking method, the reversion of terminally differentiated cells to a more plastic state has been observed. ${ }^{18}$ The process wherein terminally differentiated cells regress from a specialized function to a simpler less differentiated state, a more SC-like state, is referred to as dedifferentiation. ${ }^{19}$ Mammalian dedifferentiation is evident in myoblasts, renal cells, oligodendrocyte precursor cells, and even in germ cells. ${ }^{19}$ The process of dedifferentiation commonly involves re-entry of regenerating cells into the cell cycle process. ${ }^{20}$ Dedifferentiation allows the cell to proliferate again before re-differentiating. In this way, a variety of cell types may be replaced at the injury site. The process of cell reversion to a more pluripotent state is demonstrated experimentally by transferring somatic cell nuclei to eggs and fusing somatic cells with pluripotent cells. ${ }^{21}$ Nuclei of fertilized egg or the pluripotent SCs (PSCs) contain some putative reprogramming factors that are capable of erasing the memory of the differentiated somatic cell. More recently we learned that a combination of only four transcription factors (ie, Oct $3 / 4$, Sox2, Klf4, and c-Myc) is sufficient to revert differentiated somatic cells into an embryonic fate somewhat akin to that of ESCs. ${ }^{22}$ The critical importance of transcription factor networks in determining stemness and cell fate was thus recognized. The emergent field of nuclear reprograming has provided critical insight into a number of fundamental cell biology processes, including transdifferentiation or direct 
reprogramming. Although the two terms are often used interchangeably, there are important distinctions between the two. Transdifferentiation is a spontaneous change of cell fate that typically happens in vivo under conditions of stress or pathological insult. In contrast, direct reprogramming is induced by defined factors such as chemical compounds, transcription factors, or other artificial engineering methods. ${ }^{23}$ In other words, direct reprogramming could be defined as transdifferentiation that can only happen under stringent artificial control conditions. ${ }^{24}$

Transdifferentiation advances the notion of dedifferentiation to one step further whereby all of the cells regress to a point from where they may differentiate to multiple specialized cell types. Transdifferentiation may also bypass the pluripotent state. With the use of defined transcription factors such as Asc11/Brn2/Myt11, Gata4/Mef2c/Tbx5, and Hnf4a/ Foxa, fibroblasts may be reprogrammed to neurons, cardiomyocytes, and hepatocytes, respectively. ${ }^{25}$ Such inducible transdifferentiation process bypasses the pluripotent state and is therefore often referred to as direct reprogramming. ${ }^{26}$ Under normal physiologic conditions, the transdifferentiation process seems to be rare in mammals, although a closer look is warranted. However, during early stages of post-natal development, mouse esophagus smooth muscle may give rise to skeletal muscle tissue. ${ }^{27}$ In adults, dedifferentiation and transdifferentiation may occur naturally during the early phase of tissue repair. These subtle changes in cellular plasticity are driven by an orchestrated regulation of gene expression networks to reconstruct tissues in a sophisticated manner that avoids undesirable consequences such as neoplasia. Although the reappearance of developmental phenotype is reported during tissue regeneration, ${ }^{28}$ the molecular underpinnings remain largely elusive. What fills part of this void is the emergent observations that span the diverse phylogenetic tree of the animal kingdom, demonstrating that miRNAs play a key role in tissue repair and regeneration. ${ }^{29}$ Given their capacity to determine the functional fate of coding genes and therefore a large network of downstream signaling pathways, ${ }^{30}$ miRNAs are rapidly emerging as potential candidates for the therapeutic modulation of tissue repair and regeneration. In this context, it is of extraordinary importance that the turnover of miRNA within the cell determines its functional fate.

\section{miRNA Turnover Determines Cell Fate}

Tissue regeneration is markedly compromised with aging, and the underlying reasons remain largely elusive. ${ }^{31} \operatorname{Lin} 28 \mathrm{a}$ improve tissue repair by suppressing let-7 biogenesis and enhancing oxidative metabolism. ${ }^{31}$ Several mature miRNAs exhibit tissue-specific expression pattern, although their primary transcripts show no substantial changes in expression pattern. ${ }^{32}$ Although several aspects of global miRNA biogenesis pathways are well understood, ${ }^{5}$ the specific mechanisms regulating the expression of individual miRNAs that exhibit distinctive expression patterns in certain tissues remain unclear. ${ }^{33}$ Interestingly, fine tuning of each step of the general miRNA biogenesis pathway allows tight control of expression of specific individual miRNAs. A battery of proteins take part in executing miRNA biogenesis either by interacting with the Drosha-DGCR8 microprocessor complex, or Dicer or the miRNA precursors. ${ }^{34}$ At the microprocessor level, the p68 and p72 helicases regulate the biogenesis of approximately one-third murine pri-miRNA. ${ }^{35}$ Similarly, individual miRNA processing, such as pri-miR21 or pri-miR-7, is greatly influenced by other proteinprotein interactions such as the SMAD-p68 complex or SMAD-SMAD nuclear interacting protein 1 and splicing factor SF2/ASF. ${ }^{36}$ Similarly, heterogeneous nuclear ribonucleoprotein A1 facilitates Drosha-mediated processing by binding to the loop regions. ${ }^{36}$ The KH-type splicing regulatory protein enhances Drosha and Dicer processing by binding to the guanine triplet motifs in their terminal loops of the pri- and pre-miRNA. ${ }^{36}$ Although the effect of the Lin28 repressor is limited to let-7 family members, the nuclear factor NF90-NF45 heterodimer impairs DiGeorge syndrome critical region 8 (DGCR8) function. ${ }^{36}$ This effect is executed in a sequence-independent manner through interaction with the pri-miRNA stem loop structure. ${ }^{36}$ Finally, pri- or pre-miRNA editing by adenosine deaminases 1 and 2 may affect mature miRNA accumulation and influence miRNA-target specificity. ${ }^{36}$

\section{miRNA Biogenesis}

For a detailed review of miRNA biogenesis, please refer to the recent literature. ${ }^{34,37}$ Broadly, miRNA biogenesis involves two essential steps that produce a mature functional miRNA. Apart from the known canonical and noncanonical pathways, miRNA biogenesis from the loop sequence, tRNA-derived RNA fragments and the miRNA arm selection have now become evident. Several kilobase long pri-miRNAs along with the stem loop structure are trimmed to a 60- to 100-nt hairpin-structured precursor (the pre-miRNA) by RNase III Drosha and DGCR8 that as a multi-protein microprocessor unit guides the specificity of Drosha's cleavage activity resulting in a double stranded pre-miRNA with a 2-nt $3^{\prime}$ overhang (Figure 1). The expression and activity of Drosha and DGCR8 are subject to stringent regulation by multiple factors that in turn influence intracellular turnover of miRNAs. For example, DGCR8 stabilizes Drosha, whereas Drosha cleaves the hairpins in DGCR8 mRNA thereby inducing degradation.

The cytoplasmic export of newly generated pre-miRNA occurs via a Ran-GTP-dependent process. The $3^{\prime}$ overhang is specifically recognized by exportin 5 (XPO5), and this permits the selective cytoplasmic export of correctly processed pre-miRNA. Disruption of enzymes such as Drosha or DGCR8, which are essential for the miRNA maturation, results in rapid proliferation of cancer cells. ${ }^{38}$ In the cytoplasm, additional cleavage of pre-miRNAs near the terminal 


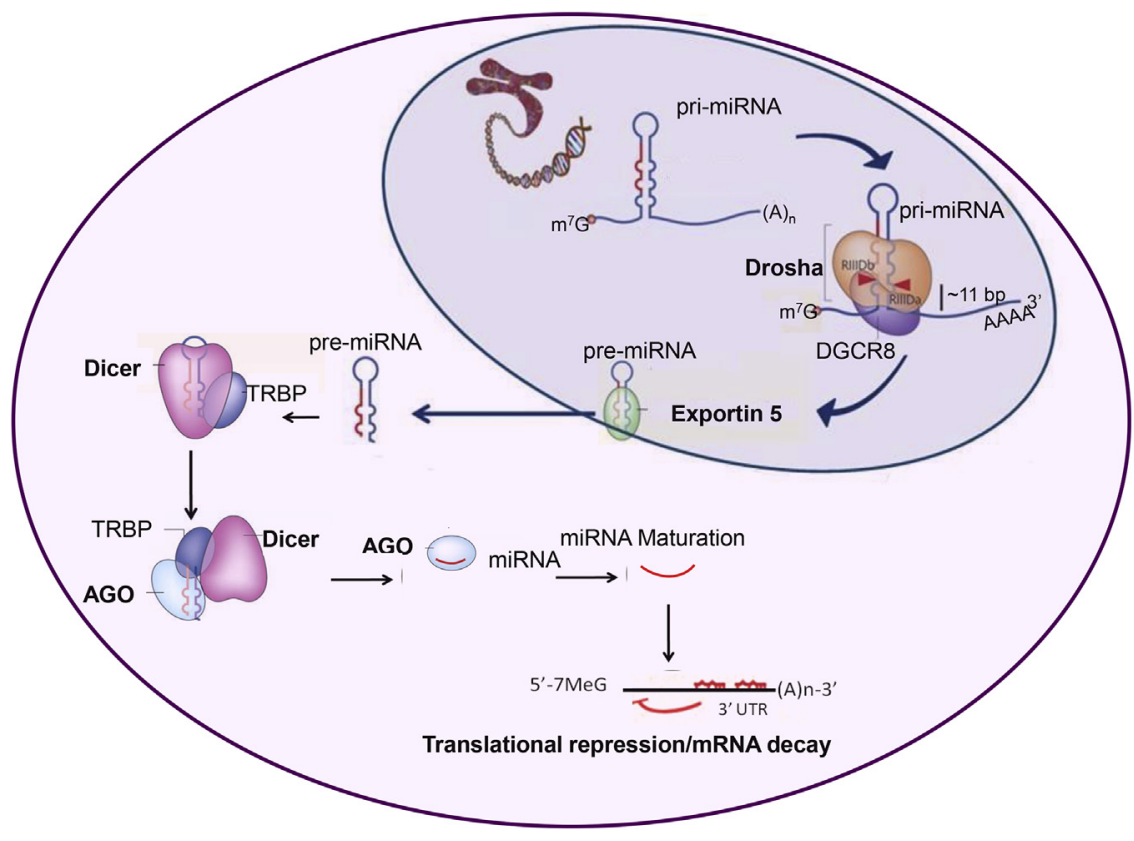

Figure 1 The miRNA biogenesis pathway. The pri-miRNA transcript is cleaved by the microprocessor complex Drosha-DGCR8 in the nucleus. The precursor hairpin pre-miRNA is exported from the nucleus by Exportin-5-Ran-GTP. In the cytoplasm, the RNaseIII Dicer forms complex with the doublestranded RNA-binding protein TRBP and AGO-2 forms the RISC. The functional strand of the mature miRNA is loaded together with $\mathrm{AGO}-2$ proteins into the RISC. The mature miRNA silences target mRNAs through mRNA cleavage, translational repression, or deadenylation, whereas the passenger strand (black) is degraded. AG0-2, argonaute-2; DGCR8, DiGeorge syndrome critical region gene 8; pre-miRNA, precursor miRNA; pri-miRNA, primary miRNA; RISC, RNA-induced silencing complex; TRBP, TAR RNA binding protein. loop is initiated by Dicer, a second RNaseIII enzyme. In mouse fetal skin, Dicer is substantially down-regulated, indicating suppressed global miRNA biogenesis that is likely to prevent silencing of numerous coding genes aimed at tissue regeneration often evident at E16. ${ }^{7}$ Dicer acts as a molecular ruler that cleaves the pre-miRNA at a specific distance from the ends produced by Drosha cleavage and generating an approximate 22-nt double-stranded miRNA duplex $\left(\mathrm{miR} / \mathrm{miR}^{*}\right)$ with a 2 -nt $3^{\prime}$ overhang. Dicer forms the RNA induced silencing complex (RISC) in combination with TAR RNA binding protein (TRBP), protein kinase RNA activator (PACT), and Argonaute (AGO) proteins. Previously, RISC processing of miRNA duplexes was thought to involve the incorporation of one strand (with the lowest $5^{\prime}$ base-pairing stability), whereas the other was degraded based on thermodynamic principles and energyindependent endonuclease-mediated selection with Ago2. Strands present in the miR-RISC complex are named based on their position in the hairpin sequence as $-5 p$ or $-3 p$. Evidence shows that the target abundance stabilizes the less-dominant strand of miRNA, implying that the target transcript regulation may affect the selection of mature miRNAs. We now know that 3p-miRNA is successfully activated if the pre-miRNA is $5^{\prime}$-capped. In addition to arm selection, the loop region of the pre-miRNA hairpin may also be used for so-called loop-miRNA, suggesting that double strands generated by typical miRNA processing are not absolutely needed for the functioning of certain miRNAs.

The synthesized miRNA targets complementary sequences in the $3^{\prime}$-UTR of its target mRNA. Functional repression depends on the extent of complementarity. If the binding is perfect, it leads to mRNA cleavage and degradation. If the binding is imperfect, it may cause translational repression. miRNAs can directly affect protein translation by targeting one or more of multiple stages such as initiation, elongation, or termination. Indirect suppression of protein synthesis by miRNA is aimed at altering stability and initiating degradation of target mRNAs by deadenylation or sequestration of the target mRNAs at cytoplasmic foci called processing bodies ( $\mathrm{P}$ bodies). mRNA turnover is thus affected. ${ }^{37}$

\section{miRNA Degradation}

Although miRNAs are globally stable with half-lives that may extend up to days, ${ }^{39}$ initial studies indicate that mature miRNAs are under the regulatory control of cis- and transacting factors. The lifetime of any given miRNA is profoundly affected by specific modifications and exonucleases. However, further investigation into the regulation of miRNA homeostasis is warranted in the following three areas: i) miRNA modifications, ii) relation between miRNA function and stability, and iii) targeted degradation of specific miRNA. ${ }^{40}$

On an as-needed basis, reversible muting of PTGS may be enacted by several miRNases (Figure 2) or exoribonucleases that may degrade cellular miRNA, thereby regulating downstream functional impact. The question is: How are miRNAs protected from exoribonucleases? Within the miRNA-RISC complex (miRISC), the miRNA is protected from ribonuclease activity because both $5^{\prime}$ and $3^{\prime}$ ends of miRNAs are buried within the AGO protein. ${ }^{41}$ AGO proteins not only enrich miRNA abundance but also conceal the miRNA as evident from structural biology studies. ${ }^{42}$ How the AGO protein unfolds to make the miRNA accessible for exoribonuclease degradation remains unknown. 


\begin{tabular}{|c|c|c|c|c|c|c|c|c|}
\hline Name & Drosha & Dicer & MCPIP1 & Argonaute & GLD-2 & PUP-2 & XRN2 & PNPase old-35 $^{\text {ol }}$ \\
\hline Type & $\begin{array}{l}\text { RNase III } \\
\text { endonuclease }\end{array}$ & $\begin{array}{l}\text { RNase III } \\
\text { endonuclease }\end{array}$ & $\begin{array}{l}\text { Zinc-finger } \mathrm{CCCH} \\
\text { type containing } 12 \mathrm{~A}\end{array}$ & $\begin{array}{l}\text { PIWI-RNase } \mathrm{H} \\
\text { endonuclease }\end{array}$ & $\begin{array}{c}\text { Poly(A) } \\
\text { polymerase }\end{array}$ & Uridyltransferase & $\begin{array}{c}5^{\prime} \text {-to-3' } \\
\text { exonuclease }\end{array}$ & $\begin{array}{l}3 \text { '-to-5' } \\
\text { exonuclease }\end{array}$ \\
\hline $\begin{array}{c}\text { Substrate } \\
\text { /site }\end{array}$ & $\mathrm{m}^{7} \mathrm{G}-\infty \mathrm{AAA}^{3}$ & pre-miRNA & pre-miRNA & $\begin{array}{l}\text { Processed } \\
\text { pre-miRNA }\end{array}$ & $\begin{array}{l}\text { miRNA } \\
5^{3}{ }^{3}\end{array}$ & pre-miRNA \& & $\begin{array}{l}\text { miRNA } \\
\widetilde{C}^{3}\end{array}$ & ${ }^{\text {miRNA }}$ \\
\hline Result & $\begin{array}{c}\text { miRNA } \\
\text { maturation }\end{array}$ & $\begin{array}{l}\text { miRNA } \\
\text { maturation }\end{array}$ & $\begin{array}{l}\text { pre-miRNA } \\
\text { degradation }\end{array}$ & $\begin{array}{c}\text { miRNA } \\
\text { maturation }\end{array}$ & $\begin{array}{l}\text { miRNA } \\
\text { stabilization }\end{array}$ & $\begin{array}{c}\text { miRNA } \\
\text { destabilization }\end{array}$ & $\begin{array}{c}\text { miRNA } \\
\text { degradation }\end{array}$ & $\begin{array}{c}\text { miRNA } \\
\text { degradation }\end{array}$ \\
\hline
\end{tabular}

Figure 2 Enzymes that act on the pre-miRNA and mature miRNA to determine miRNA turnover. The pri-miRNA transcript is processed by Drosha to generate the pre-miRNA. The miRNA biogenesis depends on the balance of productive and abortive ribonucleases such as Dicer and MCPIP1, both of which act on the same pre-miRNA. Argonaute and GLD-2 act on mature miRNA for maturation and stabilization. Similarly PUP-2, XRN-2, and PNPase old $-35^{35}$ act on mature miRNA for degradation. MCPIP1, monocyte chemotactic protein-induced protein 1; PNPase, polynucleotide phosphorylase; pre-miRNA, precursor miRNA; pri-miRNA, primary miRNA.

\section{miRNA Signature in SCs}

Deep sequencing studies have revealed that miRNA expression in naive ESCs exhibit a different signature compared with primed epiblast SCs with only one-third of the total miRNA being differentially expressed. ${ }^{43}$ miR290-295, miR17-92, and miR302/367 clusters are differentially expressed along with a cluster of large repeats on chromosome $2{ }^{43}$ Although the term induced pluripotent stem cells (iPSCs) is often referred to as nearly identical to their embryoderived counterparts, miRNA expression profiling between the human ESCs and human iPSCs demonstrate marked differences in a subset of miRNAs. ${ }^{44}$ miRNA expression in ES and reprogrammed cells (iPSCs or nuclear transfer ES cells) have been identified by genome mapping. Within these two cell types, 34 miRNAs were differentially expressed. Of these differentially expressed miRNA, miR-24 and miR-370 were upregulated in ES. ${ }^{45}$ These reports demonstrate that SCs or pluripotent cells have their own distinct signature irrespective of their origin. This observation sheds light on the intriguing potential that miRNAs may function as key drivers in regeneration. ${ }^{46}$

Loss of Dicer is embryonically lethal due to the lack of almost all PSCs. ${ }^{47}$ In vitro, ESCs with Dicer deletion do not proliferate. ${ }^{48}$ DGCR8 ablation also blunts proliferation of ESCs which go on to accumulate in the $\mathrm{G}_{1}$ phase of the cell cycle. ${ }^{49}$ Current observations lead to the notion that miRNA biogenesis is integral for tissue development and highlights the importance of specific miRNA expression that is critical for embryonic development. For example, members of the miR-290 family are productive in rescuing proliferation of DGCR8-deficient ES cells but have no effect on the differentiation defect. ${ }^{50}$ Such miRNAs are referred to as ESCC miRNAs, or ES cell-specific cell cycle regulating miRNAs. The notion that distinct stages in embryonic development are regulated by specific subsets of miRNAs is further supported by studies with let-7 miRNA demonstrating inhibition of proliferation and self-renewal of ES cells. ${ }^{51,52}$ The emerging idea therefore is that as development progresses, an increasing number of miRNA get involved resulting in a higher level of complexity as it relates to regulating relevant biological processes. ${ }^{53}$ A logical extension of this observation would be the notion that miRNAs may be used an effective resource to induce cellular reprogramming.

\section{miRNAs in Cellular Reprogramming}

The ectopic expression of Oct4, Sox2, Klf4 and c-Myc (Yamanaka factors/OSKM) may reprogram differentiated cells to a pluripotent state. ${ }^{22}$ As the molecular mechanisms underlying such cellular reprogramming unfold, the significance of miRNA in cell reprogramming is being widely recognized. miR-302 and miR-17 families are abundantly expressed in the early stages of OSKM induced pluripotency. ${ }^{54}$ Disruption of global miRNA biogenesis by ablation of Drosha, Dicer, or Ago2 substantially reduces OSKM-induced iPSC colonies in mouse embryonic fibroblasts. ${ }^{54}$ Introduction of several members of miR-290 cluster may enhance the efficiency of OSK-induced cell reprogramming, comparable with that achieved by OSKM, demonstrating that miR-290s may substitute c-Myc (Figure 3). In this context, it should be noted that the promoter region of the miR-290-295 cluster may be bound by c-MYC. ${ }^{55}$ Similar studies with ectopic expression of miR-93, miR-106b, and miR-302 cluster were successful in enhancing cell reprogramming.

In the absence of OSK factors, delivery of miR-302a, miR$302 \mathrm{~b}$, miR-302c, or miR-302d alone fails to induce the expression of epithelial markers. ${ }^{56}$ Two independent groups have now demonstrated that lentiviral expression of miR-302/ miR-367 cluster and a cocktail of miRNAs (miR-200c, miR302a-d, miR-369-3p, and miR-369-5p) may reprogram human fibroblasts to iPSCs efficiently. ${ }^{57}$ The cells that reexpressed human ESC factors featuring global gene expression analogous to human ESCs were named miRNA-iPSCs. This constitutes the first proof of principle to demonstrate that iPSCs may be obtained with miRNAs without the need for genomic integration of foreign DNA. Genomic integration increases the chances of recipient chromosomal locus modification after integration, thereby raising the possibility of 


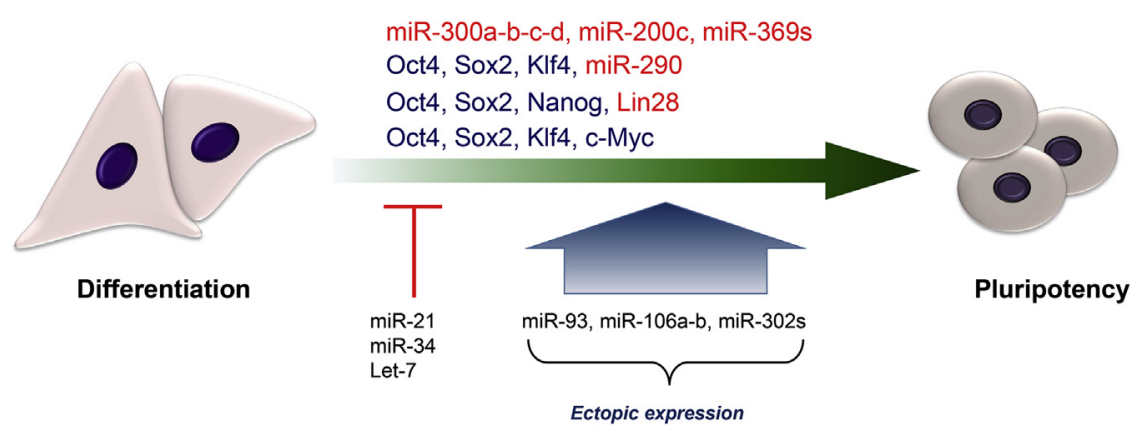

Figure 3 Schematic illustration depicting basic regulatory network of miRNA interactions aimed at pluripotency. Ectopic expression of miR-93, miR106a-b, and miR-302s induces pluripotency in differentiated cells. Apart from direct expression of core pluripotency factors such as 0ct4, Sox2, KLF4, and c-Myc, miR-300a-b-c-d, miR-200c, miR-369s are capable of inducing pluripotency. Overexpression of miR-290 may replace c-Myc during induction of pluripotency. Expression of Let-7 miRNA enacts exit of cells from the cell cycle by repressing Lin28. Expression of miR-21 and miR-34 prevents conversion of differentiated cells to their pluripotent state.

making the recipient genomic loci unstable. ${ }^{58}$ Although adenovirus-derived vectors and Sendai virus were proclaimed as safe nonintegrating methods for production of iPSCs, the statement should be used with extreme caution. Harui et al ${ }^{59}$ have reported that in established cell lines, adenoviral vectors do integrate into the genome. Thus, caution should be exercised as we seek to adopt these techniques for in vivo applications. $^{60}$ A comparison of nonintegrating nonviral methods for human somatic cell reprogramming to iPSCs is provided in Table 1. Compared with these methods, miRNAbased strategies to generate iPSCs without involving genomic integration is a much safer choice and therefore is of extraordinary therapeutic value (Table 1). ${ }^{57,61-70}$

\section{Is miR-29 a Master Regulator of Tissue Regeneration?}

In the mammalian system, the extracellular matrix (ECM) is critical for tissue regeneration. The ECM determines cell behavior by manipulating cell shape, proliferation, migration, differentiation, and death. ${ }^{71}$ Scarless regenerative healing is an intrinsic property of the fetal skin. ${ }^{72}$ Major differences in the ECM of the fetal and the adult skin account for the sharp contrast in healing phenotype between the fetus and adult skin. ${ }^{73}$ Fetal skin ECM predominantly expresses type III collagen, elevated hyaluronic acid, and elevated matrix metalloproteinase to tissue-derived inhibitor (MMP:TIMP) ratio that facilitates cell movements, turnover of ECM modulators, and tissue remodeling. ${ }^{72,74}$ One of the hallmarks of fetal skin development is the lower abundance of miRNAs caused by mechanisms that are aimed at silencing PTGS during tissue development, enabling expression of otherwise silenced coding genes that drive skin development. Of such miRNAs that are silenced during fetal development, low abundance of miR29 was reported in skin across several species. ${ }^{7,75,76}$ In humans, hsa-miR-29a and hsa-miR-29b-1 (chromosome 7) and hsa-miR-29b-2 and hsa-miR-29c (chromosome 1) are highly conserved members of the miR-29 family that share the sequence homology at the seed region (nts 2-7) that decides the fate of coding genes. PTGS of multiple ECM proteins by the miR-29a-c family is one notable example of a single miRNA family regulating multiple ECM proteins such as different collagen isoforms, laminin 1, fibrilin 1, elastin, matrix metalloproteinase 2, hyaluronic acid, chondroitin sulfate, and integrin $1{ }^{77}$ Predicted conserved binding sites for the miR$29 \mathrm{a}-\mathrm{c}$ family on the $3^{\prime}$-UTR of 20 collagen genes have been identified. $^{78}$ This property is unique to the miR-29 family because the predicted binding sites of the collagen genes are not attributed to any sequence homology in their $3^{\prime}$-untranslated region. ${ }^{78}$ In adults, members of the miR-29 family cause suppression of ECM genes, resulting in tissue repair with a scar. Dysregulation of ECM caused by lower miR-29 is associated with fibrosis development in several organs, including the heart, ${ }^{77}$ kidney ${ }^{79}$ lung, ${ }^{80}$ and liver. ${ }^{81}$ Furthermore, miR-29 influences tissue differentiation and senescence. $^{82}$ Elevated expression of miR-29 may mitigate the inhibitory effect of transforming growth factor- $\beta$ on myogenesis by targeting histone deacetylase 4, a key inhibitor of muscle differentiation. ${ }^{83}$ In adults, the elevated expression of miR-29 suppresses insulin-like growth factor-1, p85 $\alpha$, and Bmyb, leading to onset of senescence of muscle progenitor cells in vivo, thereby leading to muscle atrophy and sarcopenia. ${ }^{84}$ Targeting YY1, ${ }^{85}$ a repressor of miR-29, may therefore be a

Table 1 Comparison of Nonintegrating Nonviral Methods for the Human Somatic Cell Reprogramming to iPSCs

\begin{tabular}{lllllll}
\hline Methods & Time, days & Efficiency, $\%$ & Success, $\%$ & Pros & Cons & References \\
\hline miRNA & 20 & 0.002 & $60-70$ & Zero footprint & Validated for only one cell type & $57,61,62$ \\
mRNA & $20-25$ & $0.6-4.4$ & $20-30$ & Zero footprint & Cost, technically challenging, labor intensive & $61-64$ \\
Protein & 56 & 0.001 & NA & Zero footprint & Technically challenging, reprograming time & $61,64-66$ \\
Episomal & 30 & $0.0006-0.02$ & $80-90$ & Zero footprint & Low efficiency & $61,62,67,68$ \\
Minicircles & 15 & 0.005 & NA & Zero footprint & Validated for only one cell type & $61,64,68,69$ \\
Piggybac & $14-28$ & 0.02 & NA & Zero footprint & No data show excision of transposon from & iPSC, licensing/patent issue \\
& & & & & &
\end{tabular}

iPSC, induced pluripotent stem cell; NA, not available. 
productive strategy to accelerate skeletal myogenesis. Osteoblast differentiation is also regulated by miR-29 via targeting ECM proteins, anti-osteogenic factors and Wnt signaling antagonists. $^{42,86}$

\section{Cell Reprogramming Using miRNA}

\section{Approaches and Caution}

Synthetic locked nucleic acids conjugate oligonucleotides are useful to modify the cellular levels of any particular miRNA. ${ }^{87}$ Furthermore, overexpression of pri-miRNA or pre-miRNA with some flanking sequence may be more biologically relevant than simply using the mature miRNA sequence because the transcript may interact with the endogenous cellular machinery, ensuring correct processing and final functionality. ${ }^{88}$ A key challenge in the modulation of miRNA signaling for tissue regeneration is the selection of the right therapeutic candidates. An appropriately chosen miRNA may modulate numerous functionally convergent coding genes. ${ }^{89}$ The miRNA is capable of influencing targets at several levels in a regulatory network to deliver robust biological output. To enable this, a thorough understanding of miRNA-mRNA interactions is necessary. Developing hypotheses aimed at understanding the intricate regulatory networks with the help of in silico tools (eg, Targetscan, PicTar, mi-RANDA) and validating such hypotheses experimentally represent powerful approaches. High-throughput methods such as argonaute high-throughput sequencing of RNA isolated by cross-linking immunoprecipitation allow the study of actual miRNA-mRNA interactions in any specific biological context. The ability to properly evaluate the effect of an miRNA on a specific biological pathway will pave the way for the identification of appropriate candidates for therapeutic interventions. Because tissue regeneration is a multifaceted process, miRNA therapies must consider the differential requirements of the developmental program through which participating cells will temporally progress. Appropriate dosing and strategic targeting of specific cell populations are necessary to obtain optimal functional outcome. Because the incorporation of miRNA in the RISC complex is random in mammalian cells, any alteration in the level of a particular miRNA may also affect the activity of other miRNA by competing for incorporation into the miRISC. Cancer is associated with dysregulation of miRNA. Thus, any alteration in the miRNA pool, if not properly targeted to the tissue of interest, poses the risk of neoplastic outcome. As there is clear overlap between key genes that control pluripotency and differentiation with those genes that are integral to cancer, ${ }^{90}$ it is necessary to meticulously design miRNA-based cell reprogramming strategies for the purposes of tissue repair and regeneration. Challenges related to intelligent target selection coupled with precision in dosing and spatiotemporal modulation of miRNA targets must be addressed. There are several methods to deliver miRNA to cells, including direct injection, viral, and nonviralbased methods (Figure 4).

\section{Direct Injection}

Direct injection is one of the simplest methods to deliver miRNA and antagomiRNAs. The effect is typically shortlived because the oligonucleotides are rapidly degraded by nucleases in serum and cleared by the kidneys for their inability to bind to plasma proteins. However, a single bolus intravenous injection of locked nucleic acid-anti-miRNA may be stable for several weeks and, hence, productive. ${ }^{91}$

\section{Viral Delivery}

Virus-based miRNA delivery to cells is one of the most widely used techniques in vitro. ${ }^{92}$ The most commonly used are adenoviral, lentiviral, and retroviral vectors. Although the viral vectors ensure long-term expression of the miRNA of interest (or control of expression with inducible promoters), this approach is not friendly for clinical translation because of their inherent toxicity and immunogenicity concerns. ${ }^{93}$ Adeno-associated viral vectors are promising for in vivo delivery of miRNAs because of lower risk of toxicity and seemingly limited off-target effects.

\section{Lipid Nanoparticles}

In the biology of tissue repair and regeneration, controlled release of bioactive reagents such as growth/differentiation factors or interfering RNA is critical to directing cell fate. These bioactive reagents may be loaded in lipid nanoparticles and supported by scaffolds for sustained local delivery. ${ }^{94}$ Unlike viral vectors, lipid nanoparticles offer more flexibility in formulation and design for improved uptake by the cells. In addition, enhanced delivery to specific tissues and cells may be enabled by the incorporation of target ligands. Despite having several advantages, one of the main limitations of this approach is the absence of an appropriate mechanical support component necessary to promote tissue repair and regeneration. ${ }^{94}$

\section{Nano-Electroporation}

Nanochannel electroporation may be used as a potential method controlled delivery of specific amounts of miRNA into living cells. These devices are made of microchannels connected by nanochannels. With the use of an optical tweezer, the target cell is positioned in one microchannel, and the miRNA of interest may be placed in the second microchannel. ${ }^{95}$ The production of an intense electric field is guided by the introduction of a voltage pulse between microchannels directed at a very small area on the cell membrane. This enables controlled delivery of specific amounts of oligonucleotide driven electrophoretically through the nanochannel, cell membrane, and into the cytoplasm while defending cell viability. ${ }^{95}$ Variations in the duration of nanoelectroporation and number of pulses applied may help control dosage of cargo delivery. Although there is no reported in vivo evidence 
miRNA/anti-miRNA

mmor
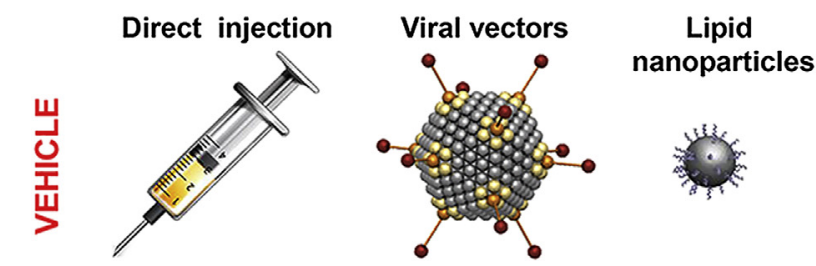

Nanoelectroporation

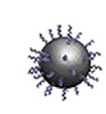

- Stable expression

\begin{tabular}{|l} 
- Biodegradable \\
- bioavailability \\
- Site specific \\
delivery \\
- Possibility of \\
scaling up \\
- Better stability \\
- Lyophilization \\
possible
\end{tabular}

- Direct and precise delivery into mammalian cells.

- Infect nondividing cells

- Better transfection efficiency.

- Less cell mortality.

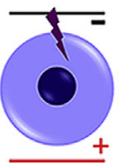

Figure 4 A comparative analysis of current approaches. Although direct injection and delivery with the use of viral vectors is widely used in in vivo and in vitro research for deciphering molecular mechanisms and pathway validation, many disadvantages limit their use in translational research for therapeutic intervention. Lipid nanoparticles are comparatively safe, but they are rapidly eliminated by the reticuloendothelial system. Nanoelectroporation offers precise delivery, better transfection efficiency, and less cell mortality.

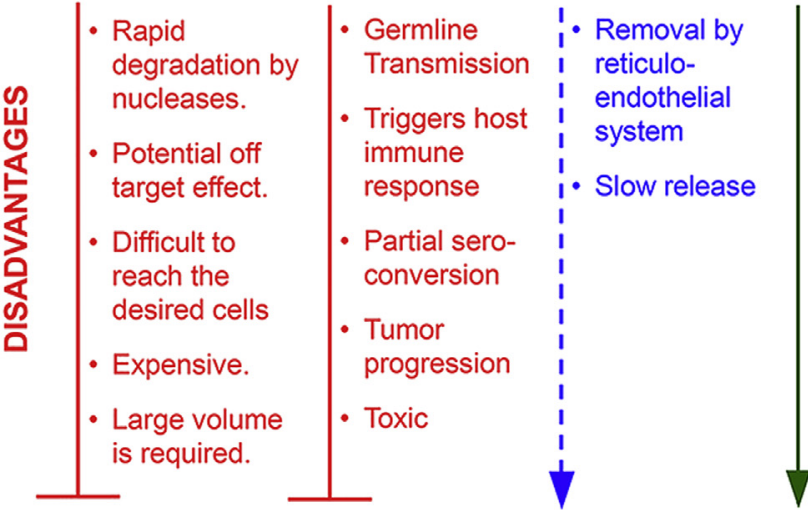 \\ Translational Research \\ (Therapeutic intervention)}

yet, such a nanochannel electroporation device has the potential to support tissue repair and regeneration in vivo.

These highly sophisticated miRNA delivery methods cannot only deliver miRNA to cells of interest but can also be used for preparing cells with a desired miRNA payload for efficient cell based therapies.

\section{miRNA in Cell-Based Therapies}

Live cells may be used to package and deliver miRNAs of interest to tissue repair and regeneration. In this approach, paracrine effects of such implanted cells may guide tissue repair and regeneration. The lifetime of such cells can be controlled by natural and engineered circuits such as introduction of death signaling pathways ${ }^{96}$ or multiple auxotrophies (metabolic dependencies). The key control modules in the cell engineering toolbox is provided in Table 2. In cell-based therapies, the notion of paracrine effects that drive repair and regeneration is well established. For example, the beneficial activities of mesenchymal SCs are mediated by the secretion of pro-regenerative and antiinflammatory growth factors in cardiac repair ${ }^{97}$ or graftversus-host disease. $^{98}$ miRNAs may be shuttled between cells packaged in small membrane-bound extracellular vesicles (EVs) (eg, exosomes, shedding vesicles, apoptotic bodies) that can then amend gene expression of their target cells. ${ }^{99}$ Thus, as a natural extension we hypothesize that cells could be used to deliver miRNAs to promote tissue regeneration. Alternatively, these EVs could be isolated and 
Table 2 Key Control Modules in Cell Engineering Toolbox

\begin{tabular}{ll}
\hline Events & Rationality \\
\hline $\begin{array}{l}\text { Cell proliferation } \\
\text { Cell death }\end{array}$ & $\begin{array}{l}\text { To ensure their survival on implantation } \\
\text { Cell migration }\end{array}$ \\
$\begin{array}{l}\text { To ensure their survival on implantation } \\
\text { To redirect cellular movement toward specific signals and sites in the body where the cells should execute their } \\
\text { Cell communication }\end{array}$ & $\begin{array}{c}\text { To reprogram cell-cell, small molecule-cell, and biologic-cell communication } \\
\text { Cell secretions }\end{array}$ \\
$\begin{array}{l}\text { For on-demand production and secretion of small molecules and biologics by engineered cells, extending beyond } \\
\text { those molecules that a cell naturally makes }\end{array}$ \\
\hline
\end{tabular}

used to deliver a pro-regenerative miRNA payload. There is some interest in the use of EVs for miRNA delivery. miR146a overexpression in human embryonic kidney 293T cells elevated the miRNA level in EVs released from cells and transfected cells. ${ }^{100}$ This approach of using cells as delivery vehicles is related to previous work that used genetically engineered MSCs to deliver proteins and to modulate in vivo tissue response. ${ }^{101}$ An advantage, particularly when using MSCs for this strategy, is that they naturally home to sites of disease or injury; therefore, they may provide a natural targeting mechanism to deliver miRNAs to the site of interest. $^{102}$ MSCs transfected with mimics of miR-124 and miR-145 have successfully delivered these miRNAs to glioma cells. MSCs loaded with miRNAs of interest are able to change gene expression and cellular behavior in vivo. ${ }^{103}$ The importance of EVs in explaining such observations remain to be understood.

\section{Tissue Engineering}

The ease by which the miRNAs may be overexpressed or repressed with sharp molecular tools renders them highly suitable for tissue reconstruction from SCs. In some instances miRNA have overcome the need for growth factors. Currently, miRNAs are widely used in the tissue engineering of cartilage, bone, and skeletal muscle. Repairing the injured cartilage is challenging, but it holds great promise for the treatment of osteoarthritis and spinal disk herniation. Although repairing major cartilage injury by using biomaterial implant and MSCs has proven to be highly successful, a critical limitation is the unstable phenotype of stem cellderived chondrocytes compared with their endogenous counterpart. Under in vivo conditions, the artificial implant undergoes terminal differentiation, followed by ossification. ${ }^{104}$ Addition of miR-133 prevents such unwanted ossification. ${ }^{105}$ Furthermore, addition of miR-675 and miR221 promotes expression of collagen II and proliferation of mature chondrocytes. In bone engineering, seeding MSCs with miR-148b mimics and miR-489 inhibitor to the osteoinductive scaffold results in increased matrix deposition and calcification. ${ }^{106}$ Human satellite cells, important in the tissue engineering of the skeletal muscle, may be treated with miR-1 and miR-206 to improve their differentiation potential. $^{107}$
Biomaterial scaffolds play a key role in scar formation associated with wound healing. These ECM-derived scaffolds, in addition to serving as physical support to promote tissue organization, resist aggressive wound contraction ${ }^{108}$ and scar tissue formation. ${ }^{109}$ These scaffolds also serve as vehicles to deliver bioactive substances such as cytokines, ${ }^{110}$ growth factors, ${ }^{109}$ living cells, ${ }^{111}$ and vectors for gene therapy. Primary fibroblasts cultured on miR-29bloaded scaffolds resulted in attenuated levels of collagen type I and III gene expression. ${ }^{112}$ Application of this scaffold to full-thickness wounds in vivo limited wound contraction and enhanced the collagen type III:I ratio and the MMP-8:TIMP-1 ratio in a dose-dependent manner. ${ }^{112}$ It is thus evident that a combination of suitable miRNAs with collagen scaffolds may help in post-injury matrix remodeling.

\section{Conclusion}

With cues from tissue development process, miRNAs may be productively used to improve tissue repair and regeneration. Such influence is executed either via endogenous repair mechanisms or by directing the activity of implanted cells at the injury site. Changes in cellular phenotype as evident during dedifferentiation, transdifferentiation, or cellular reprogramming are directly linked to miRNA function within the cell. miRNAbased approaches have opened novel avenues to produce substantial amounts of iPSC clones without the need for genomic integration. Although the science is still in its infancy, the potential applications of miRNA-based therapies for tissue engineering and regenerative medicine are promising. Compared with contemporary methods of ectopic gene expression currently used in regenerative medicine, strategies to transiently manipulate cellular miRNA by using targeted mimics and inhibitors hold substantial promise. However, off-target effects of therapeutic miRNA remain a relevant concern. Parallel advances in novel delivery technologies such as lipid nanoparticles and nanochannel electroporation are beginning to address some of the key stability and toxicity issues, thus making miRNAbased therapies more translationally relevant. Currently, there are 152 open clinical studies on miRNAs worldwide (ClinicalTrials.gov, https://clinicaltrials.gov/ct2/results? term $=m i R N A+$ and + Tissue + repair \& Search $=$ Search, last accessed March 30, 2015). Of these, six trials are on miRNA 
and tissue repair, of which three are based in the United States. The race to perfect miRNA-based therapies is one of high stakes and has the clear potential to transform reparative and regenerative medicine.

\section{References}

1. Roy S, Khanna S, Rink C, Biswas S, Sen CK: Characterization of the acute temporal changes in excisional murine cutaneous wound inflammation by screening of the wound-edge transcriptome. Physiol Genomics 2008, 34:162-184

2. Thatcher EJ, Patton JG: Small RNAs have a big impact on regeneration. RNA Biol 2010, 7:333-338

3. Nowak R: Mining treasures from 'junk DNA'. Science 1994, 263: 608-610

4. Brodersen P, Voinnet O: Revisiting the principles of microRNA target recognition and mode of action. Nat Rev Mol Cell Biol 2009, 10:141-148

5. Ha M, Kim VN: Regulation of microRNA biogenesis. Nat Rev Mol Cell Biol 2014, 15:509-524

6. Schwartzfarb E, Kirsner RS: Understanding scarring: scarless fetal wound healing as a model (comment). J Invest Dermatol 2012, 132:260

7. Cheng J, Yu H, Deng S, Shen G: MicroRNA profiling in mid- and late-gestational fetal skin: implication for scarless wound healing. Tohoku J Exp Med 2010, 221:203-209

8. Suh N, Baehner L, Moltzahn F, Melton C, Shenoy A, Chen J, Blelloch R: MicroRNA function is globally suppressed in mouse oocytes and early embryos. Curr Biol 2010, 20:271-277

9. Flemr M, Moravec M, Libova V, Sedlacek R, Svoboda P: Lin28a is dormant, functional, and dispensable during mouse oocyte-to-embryo transition. Biol Reprod 2014, 90:131

10. Heo I, Joo C, Kim Y-K, Ha M, Yoon MJ, Cho J, Yeom KH, Han J, Kim VN: TUT4 in concert with Lin28 suppresses MicroRNA biogenesis through pre-microRNA uridylation. Cell 2009, 138:696-708

11. Wang J, Conboy I: Embryonic vs. adult myogenesis: challenging the 'regeneration recapitulates development' paradigm. J Mol Cell Biol 2010, 2:1-4

12. Yunta M, Nieto-Diaz M, Esteban FJ, Caballero-Lopez M, NavarroRuiz R, Reigada D, Pita-Thomas DW, del Aguila A, MunozGaldeano T, Maza RM: MicroRNA dysregulation in the spinal cord following traumatic injury. PLoS One 2012, 7:e34534

13. Strickland ER, Woller SA, Garraway SM, Hook MA, Grau JW, Miranda RC: Regulatory effects of intermittent noxious stimulation on spinal cord injury-sensitive microRNAs and their presumptive targets following spinal cord contusion. Front Neural Circuits 2014, $8: 117$

14. Salehi S, Brereton HC, Arno MJ, Darling D, Quaglia A, O'Grady J, Heaton N, Aluvihare VR: Human liver regeneration is characterized by the coordinated expression of distinct microRNA governing cell cycle fate. Am J Transplant 2013, 13:1282-1295

15. Cheung TH, Rando TA: Molecular regulation of stem cell quiescence. Nat Rev Mol Cell Biol 2013, 14:329-340

16. Jopling C, Boue S, Izpisua Belmonte JC: Dedifferentiation, transdifferentiation and reprogramming: three routes to regeneration. Nat Rev Mol Cell Biol 2011, 12:79-89

17. Odelberg SJ: Cellular plasticity in vertebrate regeneration. Anat Rec B New Anat 2005, 287:25-35

18. Echeverri K, Clarke JD, Tanaka EM: In vivo imaging indicates muscle fiber dedifferentiation is a major contributor to the regenerating tail blastema. Dev Biol 2001, 236:151-164

19. Cai S, Fu X, Sheng Z: Dedifferentiation: a new approach in stem cell research. BioScience 2007, 57:655-662

20. Eguizabal C, Montserrat N, Veiga A, Izpisua Belmonte JC: Dedifferentiation, transdifferentiation, and reprogramming: future directions in regenerative medicine. Semin Reprod Med 2013, 31:82-94
21. Cowan CA, Atienza J, Melton DA, Eggan K: Nuclear reprogramming of somatic cells after fusion with human embryonic stem cells. Science 2005, 309:1369-1373

22. Takahashi K, Yamanaka S: Induction of pluripotent stem cells from mouse embryonic and adult fibroblast cultures by defined factors. Cell 2006, 126:663-676

23. Graf T: Historical origins of transdifferentiation and reprogramming. Cell Stem Cell 2011, 9:504-516

24. Takahashi K: Cellular reprogramming-lowering gravity on Waddington's epigenetic landscape. J Cell Sci 2012, 125:2553-2560

25. Ieda M: Direct reprogramming into desired cell types by defined factors. Keio J Med 2013, 62:74-82

26. Kelaini S, Cochrane A, Margariti A: Direct reprogramming of adult cells: avoiding the pluripotent state. Stem Cells Cloning 2014, 7: $19-29$

27. Patapoutian A, Wold BJ, Wagner RA: Evidence for developmentally programmed transdifferentiation in mouse esophageal muscle. Science 1995, 270:1818-1821

28. Poss KD: Advances in understanding tissue regenerative capacity and mechanisms in animals. Nat Rev Genet 2010, 11:710-722

29. Frith JE, Porrello ER, Cooper-White JJ: Concise review: new frontiers in microRNA-based tissue regeneration. Stem Cells Transl Med 2014, 3:969-976

30. Gusev Y: Computational methods for analysis of cellular functions and pathways collectively targeted by differentially expressed microRNA. Methods 2008, 44:61-72

31. Shyh-Chang N, Zhu H, Yvanka de Soysa T, Shinoda G, Seligson MT, Tsanov KM, Nguyen L, Asara JM, Cantley LC, Daley GQ: Lin28 enhances tissue repair by reprogramming cellular metabolism. Cell 2013, 155:778-792

32. Choudhury NR, de Lima Alves F, de Andres-Aguayo L, Graf T, Caceres JF, Rappsilber J, Michlewski G: Tissue-specific control of brain-enriched miR-7 biogenesis. Genes Dev 2013, 27:24-38

33. Davis BN, Hata A: Regulation of MicroRNA Biogenesis: a miRiad of mechanisms. Cell Commun Signal 2009, 7:18

34. Winter J, Jung S, Keller S, Gregory RI, Diederichs S: Many roads to maturity: microRNA biogenesis pathways and their regulation. Nat Cell Biol 2009, 11:228-234

35. O'Donnell KA, Wentzel EA, Zeller KI, Dang CV, Mendell JT: c-Myc-regulated microRNAs modulate E2F1 expression. Nature 2005, 435:839-843

36. Krol J, Loedige I, Filipowicz W: The widespread regulation of microRNA biogenesis, function and decay. Nat Rev Genet 2010, 11: 597-610

37. Ghatak S, Sen CK: MicroRNA biogenesis in regenerative medicine. MicroRNA in regenerative medicine. Edited by Sen CK. Oxford, Academic Press, 2015, pp 3-46

38. Ventura A, Jacks T: MicroRNAs and cancer: short RNAs go a long way. Cell 2009, 136:586-591

39. van Rooij E, Sutherland LB, Qi X, Richardson JA, Hill J, Olson EN: Control of stress-dependent cardiac growth and gene expression by a microRNA. Science 2007, 316:575-579

40. Kai ZS, Pasquinelli AE: MicroRNA assassins: factors that regulate the disappearance of miRNAs. Nat Struct Mol Biol 2010, 17: $5-10$

41. Diederichs S, Haber DA: Dual role for argonautes in microRNA processing and posttranscriptional regulation of microRNA expression. Cell 2007, 131:1097-1108

42. Wang H, Garzon R, Sun H, Ladner KJ, Singh R, Dahlman J, Cheng A, Hall BM, Qualman SJ, Chandler DS, Croce CM, Guttridge DC: NF-kappaB-YY1-miR-29 regulatory circuitry in skeletal myogenesis and rhabdomyosarcoma. Cancer Cell 2008, 14:369-381

43. Jouneau A, Ciaudo C, Sismeiro O, Brochard V, Jouneau L, Vandormael-Pournin S, Coppee JY, Zhou Q, Heard E, Antoniewski C, Cohen-Tannoudji M: Naive and primed murine pluripotent stem cells have distinct miRNA expression profiles. RNA 2012, 18:253-264 
44. Wilson KD, Venkatasubrahmanyam S, Jia F, Sun N, Butte AJ, Wu JC: MicroRNA profiling of human-induced pluripotent stem cells. Stem Cells Dev 2009, 18:749-758

45. Zhao B, Yang D, Jiang J, Li J, Fan C, Huang M, Fan Y, Jin Y, Jin Y: Genome-wide mapping of miRNAs expressed in embryonic stem cells and pluripotent stem cells generated by different reprogramming strategies. BMC Genomics 2014, 15:488

46. Hatfield SD, Shcherbata HR, Fischer KA, Nakahara K, Carthew RW, Ruohola-Baker H: Stem cell division is regulated by the microRNA pathway. Nature 2005, 435:974-978

47. Bernstein E, Kim SY, Carmell MA, Murchison EP, Alcorn H, Li MZ, Mills AA, Elledge SJ, Anderson KV, Hannon GJ: Dicer is essential for mouse development. Nat Genet 2003, 35:215-217

48. Murchison EP, Partridge JF, Tam OH, Cheloufi S, Hannon GJ: Characterization of Dicer-deficient murine embryonic stem cells. Proc Natl Acad Sci U S A 2005, 102:12135-12140

49. Wang Y, Medvid R, Melton C, Jaenisch R, Blelloch R: DGCR8 is essential for microRNA biogenesis and silencing of embryonic stem cell self-renewal. Nat Genet 2007, 39:380-385

50. Wang Y, Sheng G, Juranek S, Tuschl T, Patel DJ: Structure of the guide-strand-containing argonaute silencing complex. Nature 2008, 456:209-213

51. Melton C, Judson RL, Blelloch R: Opposing microRNA families regulate self-renewal in mouse embryonic stem cells. Nature 2010, 463:621-626

52. Lehrbach NJ, Armisen J, Lightfoot HL, Murfitt KJ, Bugaut A, Balasubramanian S, Miska EA: LIN-28 and the poly(U) polymerase PUP-2 regulate let-7 microRNA processing in Caenorhabditis elegans. Nat Struct Mol Biol 2009, 16:1016-1020

53. Wienholds E, Plasterk RH: MicroRNA function in animal development. FEBS Lett 2005, 579:5911-5922

54. Li Z, Yang CS, Nakashima K, Rana TM: Small RNAmediated regulation of iPS cell generation. EMBO J 2011, 30:823-834

55. Judson RL, Babiarz JE, Venere M, Blelloch R: Embryonic stem cellspecific microRNAs promote induced pluripotency. Nat Biotechnol 2009, 27:459-461

56. Subramanyam D, Lamouille S, Judson RL, Liu JY, Bucay N, Derynck R, Blelloch R: Multiple targets of miR-302 and miR-372 promote reprogramming of human fibroblasts to induced pluripotent stem cells. Nat Biotechnol 2011, 29:443-448

57. Miyoshi N, Ishii H, Nagano H, Haraguchi N, Dewi DL, Kano Y, Nishikawa S, Tanemura M, Mimori K, Tanaka F, Saito T, Nishimura J, Takemasa I, Mizushima T, Ikeda M, Yamamoto H, Sekimoto M, Doki Y, Mori M: Reprogramming of mouse and human cells to pluripotency using mature microRNAs. Cell Stem Cell 2011, 8:633-638

58. Wurtele H, Little KC, Chartrand P: Illegitimate DNA integration in mammalian cells. Gene Ther 2003, 10:1791-1799

59. Harui A, Suzuki S, Kochanek S, Mitani K: Frequency and stability of chromosomal integration of adenovirus vectors. J Virol 1999, 73: $6141-6146$

60. Schagen FH, Rademaker HJ, Fallaux FJ, Hoeben RC: Insertion vectors for gene therapy. Gene Ther 2000, 7:271-272

61. Rao MS, Malik N: Assessing iPSC reprogramming methods for their suitability in translational medicine. J Cell Biochem 2012, 113: 3061-3068

62. Schlaeger TM, Daheron L, Brickler TR, Entwisle S, Chan K, Cianci A, DeVine A, Ettenger A, Fitzgerald K, Godfrey M, Gupta D, McPherson J, Malwadkar P, Gupta M, Bell B, Doi A, Jung N, Li X, Lynes MS, Brookes E, Cherry AB, Demirbas D, Tsankov AM, Zon LI, Rubin LL, Feinberg AP, Meissner A, Cowan CA, Daley GQ: A comparison of non-integrating reprogramming methods. Nat Biotechnol 2015, 33:58-63

63. Warren L, Ni Y, Wang J, Guo X: Feeder-free derivation of human induced pluripotent stem cells with messenger RNA. Sci Rep 2012, 2: 657
64. Li J, Song W, Pan G, Zhou J: Advances in understanding the cell types and approaches used for generating induced pluripotent stem cells. J Hematol Oncol 2014, 7:50

65. Stadtfeld M, Hochedlinger K: Induced pluripotency: history, mechanisms, and applications. Genes Dev 2010, 24:2239-2263

66. Zhou H, Wu S, Joo JY, Zhu S, Han DW, Lin T, Trauger S, Bien G, Yao S, Zhu Y, Siuzdak G, Scholer HR, Duan L, Ding S: Generation of induced pluripotent stem cells using recombinant proteins. Cell Stem Cell 2009, 4:381-384

67. Yu J, Hu K, Smuga-Otto K, Tian S, Stewart R, Slukvin II, Thomson JA: Human induced pluripotent stem cells free of vector and transgene sequences. Science 2009, 324:797-801

68. O'Doherty R, Greiser U, Wang W: Nonviral methods for inducing pluripotency to cells. Biomed Res Int 2013, 2013:705902

69. Jia F, Wilson KD, Sun N, Gupta DM, Huang M, Li Z, Panetta NJ, Chen ZY, Robbins RC, Kay MA, Longaker MT, Wu JC: A nonviral minicircle vector for deriving human iPS cells. Nat Methods 2010, 7 : 197-199

70. Woltjen K, Michael IP, Mohseni P, Desai R, Mileikovsky M, Hamalainen R, Cowling R, Wang W, Liu P, Gertsenstein M, Kaji K, Sung HK, Nagy A: piggyBac transposition reprograms fibroblasts to induced pluripotent stem cells. Nature 2009, 458:766-770

71. Daley WP, Peters SB, Larsen M: Extracellular matrix dynamics in development and regenerative medicine. J Cell Sci 2008, 121:255-264

72. Larson BJ, Longaker MT, Lorenz HP: Scarless fetal wound healing: a basic science review. Plast Reconstr Surg 2010, 126:1172-1180

73. Tang QM, Chen JL, Shen WL, Yin Z, Liu HH, Fang Z, Heng BC, Ouyang HW, Chen X: Fetal and adult fibroblasts display intrinsic differences in tendon tissue engineering and regeneration. Sci Rep 2014, 4:5515

74. Longaker MT, Whitby DJ, Ferguson MW, Lorenz HP, Harrison MR, Adzick NS: Adult skin wounds in the fetal environment heal with scar formation. Ann Surg 1994, 219:65-72

75. Huang TH, Zhu MJ, Li XY, Zhao SH: Discovery of porcine microRNAs and profiling from skeletal muscle tissues during development. PLoS One 2008, 3:e3225

76. Wessels JM, Edwards AK, Khalaj K, Kridli RT, Bidarimath M, Tayade C: The microRNAome of pregnancy: deciphering miRNA networks at the maternal-fetal interface. PLoS One 2013, 8:e72264

77. van Rooij E, Sutherland LB, Thatcher JE, DiMaio JM, Naseem RH, Marshall WS, Hill JA, Olson EN: Dysregulation of microRNAs after myocardial infarction reveals a role of miR-29 in cardiac fibrosis. Proc Natl Acad Sci U S A 2008, 105:13027-13032

78. Liu Y, Taylor NE, Lu L, Usa K, Cowley AW Jr, Ferreri NR, Yeo NC, Liang M: Renal medullary microRNAs in Dahl salt-sensitive rats: miR-29b regulates several collagens and related genes. Hypertension 2010, 55:974-982

79. Qin W, Chung AC, Huang XR, Meng XM, Hui DS, Yu CM, Sung JJ, Lan HY: TGF-beta/Smad3 signaling promotes renal fibrosis by inhibiting miR-29. J Am Soc Nephrol 2011, 22:1462-1474

80. Pandit KV, Milosevic J, Kaminski N: MicroRNAs in idiopathic pulmonary fibrosis. Transl Res 2011, 157:191-199

81. Roderburg C, Urban GW, Bettermann K, Vucur M, Zimmermann H, Schmidt S, Janssen J, Koppe C, Knolle P, Castoldi M, Tacke F, Trautwein C, Luedde T: Micro-RNA profiling reveals a role for miR29 in human and murine liver fibrosis. Hepatology 2011, 53:209-218

82. Schraml E, Grillari J: From cellular senescence to age-associated diseases: the miRNA connection. Longev Healthspan 2012, 1:10

83. Winbanks CE, Wang B, Beyer C, Koh P, White L, Kantharidis P, Gregorevic P: TGF-beta regulates miR-206 and miR-29 to control myogenic differentiation through regulation of HDAC4. J Biol Chem 2011, 286:13805-13814

84. Hu Z, Klein JD, Mitch WE, Zhang L, Martinez I, Wang XH: MicroRNA-29 induces cellular senescence in aging muscle through multiple signaling pathways. Aging (Albany NY) 2014, 6:160-175

85. Li Z, Hassan MQ, Jafferji M, Aqeilan RI, Garzon R, Croce CM, van Wijnen AJ, Stein JL, Stein GS, Lian JB: Biological functions of 
miR-29b contribute to positive regulation of osteoblast differentiation. J Biol Chem 2009, 284:15676-15684

86. Kapinas K, Kessler C, Ricks T, Gronowicz G, Delany AM: miR-29 modulates Wnt signaling in human osteoblasts through a positive feedback loop. J Biol Chem 2010, 285:25221-25231

87. Ameres SL, Horwich MD, Hung JH, Xu J, Ghildiyal M, Weng Z, Zamore PD: Target RNA-directed trimming and tailing of small silencing RNAs. Science 2010, 328:1534-1539

88. Park JE, Heo I, Tian Y, Simanshu DK, Chang H, Jee D, Patel DJ, Kim VN: Dicer recognizes the 5' end of RNA for efficient and accurate processing. Nature 2011, 475:201-205

89. Lim LP, Lau NC, Garrett-Engele P, Grimson A, Schelter JM, Castle J, Bartel DP, Linsley PS, Johnson JM: Microarray analysis shows that some microRNAs downregulate large numbers of target mRNAs. Nature 2005, 433:769-773

90. Muller FJ, Laurent LC, Kostka D, Ulitsky I, Williams R, Lu C, Park IH, Rao MS, Shamir R, Schwartz PH, Schmidt NO, Loring JF: Regulatory networks define phenotypic classes of human stem cell lines. Nature 2008, 455:401-405

91. Hullinger TG, Montgomery RL, Seto AG, Dickinson BA, Semus HM, Lynch JM, Dalby CM, Robinson K, Stack C, Latimer PA, Hare JM, Olson EN, van Rooij E: Inhibition of miR-15 protects against cardiac ischemic injury. Circ Res 2012, 110:71-81

92. van Rooij E, Purcell AL, Levin AA: Developing microRNA therapeutics. Circ Res 2012, 110:496-507

93. Liu YP, Berkhout B: miRNA cassettes in viral vectors: problems and solutions. Biochim Biophys Acta 2011, 1809:732-745

94. Santo VE, Gomes ME, Mano JF, Reis RL: From nano- to macroscale: nanotechnology approaches for spatially controlled delivery of bioactive factors for bone and cartilage engineering. Nanomedicine (Lond) 2012, 7:1045-1066

95. Boukany PE, Morss A, Liao WC, Henslee B, Jung H, Zhang X, Yu B, Wang X, Wu Y, Li L, Gao K, Hu X, Zhao X, Hemminger O, Lu W, Lafyatis GP, Lee LJ: Nanochannel electroporation delivers precise amounts of biomolecules into living cells. Nat Nanotechnol 2011, 6:747-754

96. Di Stasi A, Tey SK, Dotti G, Fujita Y, Kennedy-Nasser A, Martinez C, Straathof K, Liu E, Durett AG, Grilley B, Liu H, Cruz CR, Savoldo B, Gee AP, Schindler J, Krance RA, Heslop HE, Spencer DM, Rooney CM, Brenner MK: Inducible apoptosis as a safety switch for adoptive cell therapy. N Engl J Med 2011, 365:1673-1683

97. Leskela HV, Satta J, Oiva J, Eriksen H, Juha R, Korkiamaki P, Ivaska KK, Soini Y, Lehenkari P: Calcification and cellularity in human aortic heart valve tissue determine the differentiation of bonemarrow-derived cells. J Mol Cell Cardiol 2006, 41:642-649

98. Hoogduijn MJ, Popp F, Verbeek R, Masoodi M, Nicolaou A, Baan C, Dahlke MH: The immunomodulatory properties of mesenchymal stem cells and their use for immunotherapy. Int Immunopharmacol 2010, 10:1496-1500

99. Zhang Y, Liu D, Chen X, Li J, Li L, Bian Z, Sun F, Lu J, Yin Y, Cai X, Sun Q, Wang K, Ba Y, Wang Q, Wang D, Yang J, Liu P, Xu T, Yan Q, Zhang J, Zen K, Zhang CY: Secreted monocytic miR150 enhances targeted endothelial cell migration. Mol Cell 2010, 39: $133-144$
100. Guduric-Fuchs J, O’Connor A, Camp B, O’Neill CL, Medina RJ, Simpson DA: Selective extracellular vesicle-mediated export of an overlapping set of microRNAs from multiple cell types. BMC Genomics 2012, 13:357

101. Haider H, Jiang S, Idris NM, Ashraf M: IGF-1-overexpressing mesenchymal stem cells accelerate bone marrow stem cell mobilization via paracrine activation of SDF-1alpha/CXCR4 signaling to promote myocardial repair. Circ Res 2008, 103:1300-1308

102. Chapel A, Bertho JM, Bensidhoum M, Fouillard L, Young RG, Frick J, Demarquay C, Cuvelier F, Mathieu E, Trompier F, Dudoignon N, Germain C, Mazurier C, Aigueperse J, Borneman J, Gorin NC, Gourmelon P, Thierry D: Mesenchymal stem cells home to injured tissues when co-infused with hematopoietic cells to treat a radiationinduced multi-organ failure syndrome. J Gene Med 2003, 5:1028-1038

103. Lee HK, Finniss S, Cazacu S, Bucris E, Ziv-Av A, Xiang C, Bobbitt K, Rempel SA, Hasselbach L, Mikkelsen T, Slavin S, Brodie C: Mesenchymal stem cells deliver synthetic microRNA mimics to glioma cells and glioma stem cells and inhibit their cell migration and self-renewal. Oncotarget 2013, 4:346-361

104. Hollander AP, Dickinson SC, Kafienah W: Stem cells and cartilage development: complexities of a simple tissue. Stem Cells 2010, 28: 1992-1996

105. Zhang Y, Xie RL, Croce CM, Stein JL, Lian JB, van Wijnen AJ, Stein GS: A program of microRNAs controls osteogenic lineage progression by targeting transcription factor Runx2. Proc Natl Acad Sci U S A 2011, 108:9863-9868

106. Mariner PD, Johannesen E, Anseth KS: Manipulation of miRNA activity accelerates osteogenic differentiation of hMSCs in engineered 3D scaffolds. J Tissue Eng Regen Med 2012, 6:314-324

107. Koning M, Werker PM, van der Schaft DW, Bank RA, Harmsen MC: MicroRNA-1 and microRNA-206 improve differentiation potential of human satellite cells: a novel approach for tissue engineering of skeletal muscle. Tissue Eng Part A 2012, 18:889-898

108. Yannas IV, Burke JF, Orgill DP, Skrabut EM: Wound tissue can utilize a polymeric template to synthesize a functional extension of skin. Science 1982, 215:174-176

109. Formiga FR, Pelacho B, Garbayo E, Abizanda G, Gavira JJ, SimonYarza T, Mazo M, Tamayo E, Jauquicoa C, Ortiz-de-Solorzano C, Prosper F, Blanco-Prieto MJ: Sustained release of VEGF through PLGA microparticles improves vasculogenesis and tissue remodeling in an acute myocardial ischemia-reperfusion model. J Control Release 2010, 147:30-37

110. Ghahary A, Tredget EE, Shen Q, Kilani RT, Scott PG, Takeuchi M: Liposome associated interferon-alpha- $2 \mathrm{~b}$ functions as an antifibrogenic factor in dermal wounds in the guinea pig. Mol Cell Biochem 2000, 208:129-137

111. Hoban DB, Newland B, Moloney TC, Howard L, Pandit A, Dowd E: The reduction in immunogenicity of neurotrophin overexpressing stem cells after intra-striatal transplantation by encapsulation in an in situ gelling collagen hydrogel. Biomaterials 2013, 34:9420-9429

112. Monaghan M, Browne S, Schenke-Layland K, Pandit A: A collagenbased scaffold delivering exogenous microrna-29B to modulate extracellular matrix remodeling. Mol Ther 2014, 22:786-796 